\title{
Screening and Morphological Characterization of Melons for Resistance to Fusarium oxysporum f.sp. melonis Race 1.2
}

\author{
Hela Chikh-Rouhou, Rafael González-Torres, and José María Alvarez ${ }^{1}$ \\ Centro de Investigación y Tecnología Agroalimentaria (CITA), Horticultura, \\ Avda. de Montañana 930, 50059 Zaragoza, Spain
}

\author{
Ali Oumouloud \\ Institut Agronomique et Vétérinaire Hassan II, Complexe Horticole d'Agadir \\ BP 18/S 80.000 - Agadir, Morocco
}

Additional index words. fusarium wilt, partial resistance, inoculation methods, fruit characters

\begin{abstract}
A total of 110 melon accessions with different geographical origins (18 countries) were screened for resistance to Fusarium oxysporum f.sp. melonis race 1.2 (pathotypes 1.2Y and 1.2W) using two artificial inoculation procedures. Twelve accessions showed some resistance to one or both strains. Three Japanese accessions, Shiro Uri Okayama (var. conomon), Kogane Nashi Makuwa, and C-211 (var. makuwa), and a Portuguese accession, BG-5384 (var. cantalupensis), showed the highest levels of resistance to both strains. The remaining eight accessions (all var. inodorus) had some level of partial resistance to $1.2 \mathrm{~W}$ only. To our knowledge, this is the first time a high level of resistance to $F$. oxysporum f.sp. melonis race 1.2 has been identified in melon accessions of Western origin. The morphological traits of the 12 accessions that showed partial resistance were characterized to assess their suitability as resistance sources in melon breeding programs. Because most of the Western commercial cultivars belong to the cantalupensis, reticulatus, or inodorus botanical varieties, the resistant accessions from these varieties seem to be the most useful sources of resistance in breeding programs for developing melon cultivars of these types resistant to fusarium wilt race 1.2. The Portuguese accession BG-5384 had a high level of resistance within the Western types, and its morphological characteristics were fairly similar to some of the Western commercial cultivars.
\end{abstract}

Melon is an important horticultural crop across the world, and the fruits of different cultivars show considerable intraspecific diversity. This diversity is exemplified by the morphological variation in fruit characteristics such as size, color, and taste with Cucumis melo being considered the most variable species within the genus (Bates and Robinson, 1995; Jeffrey, 1980; Mallick and Masui, 1986).

Fusarium wilt, caused by Fusarium oxysporum f.sp. melonis (F.o.m.), is a limiting factor for melon production worldwide (Martyn and Gordon, 1996; Mas et al., 1981). Based on the host resistance genes associated with variants of this pathogen, Risser et al. (1976) classified the F.o.m. isolates into four physiological races designated $0,1,2$, and 1.2. Two dominant resistance genes, Fom- 1 and Fom-2, control resistance to races 0 and 2 and

\footnotetext{
Received for publication 6 Apr. 2010. Accepted for publication 16 May 2010.

This study was funded by grant AGL 2008-05687C02-02 from the Spanish Ministry of Science and Innovation. H. Chikh-Rouhou acknowledges a fellowship from the IAECI (Spanish Foreing Affaires Ministry).

${ }^{1}$ To whom reprint requests should be addressed; e-mail jmalvarez@aragon.es.
}

0 and 1, respectively. F.o.m. isolates classified as race 1.2 are able to induce disease in melon lines carrying the described resistance genes and were further divided into pathotype $1.2 \mathrm{Y}$, which induces yellowing symptoms before the death of the plants, and pathotype $1.2 \mathrm{~W}$, which produces wilting and death without yellowing symptoms.

Many sources of resistance to F.o.m. races 0,1 , and 2 have been reported (Alvarez et al., 2005; Pitrat et al., 1996). However, partial resistance to race 1.2 controlled by polygenic recessive genes was only detected in a few Far Eastern accessions such as Ogon 9 and Kogane Nashi Makuwa (Perchepied and Pitrat, 2004; Risser and Rode, 1973), which are organoleptically far from the melons accepted by Western markets. These accessions allowed breeding of partially resistant lines to race 1.2 of F.o.m. such as Isabelle (Risser and Rode, 1973) and, more recently, two double-haploid lines, Nad-1 and Nad-2, that show higher resistance than the other genotypes (Ficcadenti et al., 2002). Resistance of the melon hybrid 'Dinero' used in this work has the same origin.

Recently, Herman and Perl-Treves (2007) reported a near complete resistance to race 1.2 of F.o.m. conferred by two complementary recessive genes in the breeding line BIZ, and Oumouloud et al. (2009) reported the possibility of partial resistance to this race within some inodorus accessions of Western origin.

It is important to have many different resistance sources because adaptations by fusarium can render specific resistance genes ineffective. To this end, a screening was conducted to detect new melon accessions resistant to race 1.2 of F.o.m. within Cucumis melo germplasm collections. Additionally, the genotypes in which resistance was found were characterized for several agronomic traits to assess their usefulness in melon breeding programs. These programs would carry out the selection and breeding of resistant genotypes with high yields and other traits attractive to markets.

\section{Materials and Methods}

\section{Plant materials and fungal isolates}

A total of 110 accessions of Cucumis melo from different geographical origins were provided by Estación Experimental "La Mayora" Málaga (Spain), CITA Zaragoza (Spain), and Centro Nacional de Recursos Fitogenéticos, Madrid, Spain (Table 1), and they were evaluated for resistance to F.o.m. race 1.2. Control lines included: Charentais T, which is susceptible to all F.o.m. races; Charentais Fom 1, which is resistant to races 0 and 2; Charentais Fom 2, which is resistant to races 0 and 1; Cum-334, which carries the Fom-1 and $F o m-2$ alleles that confer total resistance to races 0,1 , and 2; and hybrid $F_{1}$ 'Dinero' (Obt. Syngenta), which is resistant to both pathotypes of race 1.2 and carries Fom- 1 and Fom-2.

For inoculum preparation, F.o.m. isolates Fom 0125 and Fom $37 \mathrm{mls}$, belonging to pathotypes $1.2 \mathrm{Y}$ and $1.2 \mathrm{~W}$, respectively, were used. Fungi were grown in potato dextrose broth on a rotary shaker for $10 \mathrm{~d}$ at room temperature. Conidia were harvested by filtration through an autoclaved nylon mesh. Spore concentration was determined using a hemocytometer and adjusted to the appropriate concentration by diluting with sterile distilled water.

\section{Inoculation procedures}

Continuous-dip inoculation. The 110 accessions reported in Table 1 were screened for resistance using the inoculation procedure previously described by Freeman and Rodriguez (1993). Melon seeds from the tested accessions were sown into sterilized sand and grown in a growth chamber $\left(24^{\circ} \mathrm{C}\right.$ : 16 -h day, $16^{\circ} \mathrm{C}: 8$-h night). When the first true leaf began to emerge, seedlings were uprooted, and their roots were washed under running tap water. The plants were introduced into plastic pots containing $200 \mathrm{~mL}$ of a Hoagland nutrient solution (Gamborg and Wetter, 1975) and a conidial suspension $\left(3 \times 10^{6}\right.$ conidia $\left./ \mathrm{mL}\right)$. Pots were then placed on an orbital shaker operating at $120 \mathrm{rpm}$ in a growth chamber $\left(28^{\circ} \mathrm{C}: 16-\mathrm{h}\right.$ day, $20{ }^{\circ} \mathrm{C}$ : 8 -h night). Twelve seedlings per pathotype and accession were inoculated. The symptom evaluation was done $15 \mathrm{~d}$ after 
Table 1. Mean reactions of 110 melon accessions to inoculation with pathotypes $1.2 \mathrm{Y}$ and $1.2 \mathrm{~W}$ of Fusarium oxysporum f.sp. melonis. ${ }^{\mathrm{z}}$

\begin{tabular}{|c|c|c|c|c|c|c|c|c|c|c|c|}
\hline Accession & Origin $^{y}$ & $1.2 \mathrm{Y}$ & $1.2 \mathrm{~W}$ & Accession & Origin & $1.2 \mathrm{Y}$ & $1.2 \mathrm{~W}$ & Accession & Origin & $1.2 \mathrm{Y}$ & $1.2 \mathrm{~W}$ \\
\hline Shiro Uri Okayama & $\mathrm{J}$ & $1.1 \pm 0.3^{\mathrm{x}, \mathrm{w}}$ & $1.5 \pm 0.5$ & C-170 & $\mathrm{G}$ & $3.7 \pm 0.4$ & $3.3 \pm 0.5$ & Loperos & $\mathrm{S}$ & $4.0 \pm 0.0$ & $3.8 \pm 0.4$ \\
\hline Kog.Nashi Makuwa & $\mathrm{J}$ & $1.2 \pm 0.4$ & $1.0 \pm 0.0$ & BG-045 & $\mathrm{S}$ & $3.8 \pm 0.4$ & $3.1 \pm 0.4$ & Inverno & $\mathrm{S}$ & $4.0 \pm 0.0$ & $3.8 \pm 0.6$ \\
\hline Baza & $\mathrm{S}$ & $1.9 \pm 0.4$ & $1.5 \pm 0.6$ & Amarillo C. Pinta & $\mathrm{S}$ & $3.8 \pm 0.6$ & $3.1 \pm 0.4$ & Ariso & $\mathrm{S}$ & $4.0 \pm 0.0$ & $3.8 \pm 0.5$ \\
\hline BG-5384 & $\mathrm{P}$ & $2.0 \pm 0.0$ & $1.5 \pm 0.5$ & Amarillo & $\mathrm{S}$ & $3.8 \pm 0.6$ & $3.1 \pm 0.3$ & Tortuga & $\mathrm{S}$ & $4.0 \pm 0.0$ & $3.9 \pm 0.6$ \\
\hline C-211 & $\mathrm{J}$ & $2.4 \pm 0.7$ & $1.9 \pm 0.4$ & Encin 4070 & $\mathrm{~S}$ & $3.8 \pm 0.4$ & $3.3 \pm 0.4$ & C-174 & $\mathrm{R}$ & $4.0 \pm 0.0$ & $3.9 \pm 0.3$ \\
\hline Encin 4108 & S & $2.7 \pm 0.8$ & $2.5 \pm 0.8$ & De Chapa & $\mathrm{S}$ & $3.8 \pm 0.4$ & $3.3 \pm 1.0$ & BG-5383 & $\mathrm{P}$ & $4.0 \pm 0.0$ & $3.9 \pm 0.4$ \\
\hline Korça & $\mathrm{R}$ & $2.8 \pm 0.7$ & $1.5 \pm 0.6$ & C-267 & $\mathrm{U}$ & $3.8 \pm 0.4$ & $3.4 \pm 0.5$ & BG-4099 & $\mathrm{S}$ & $4.0 \pm 0.0$ & $3.9 \pm 0.3$ \\
\hline C-181 & $\mathrm{J}$ & $2.8 \pm 0.8$ & $2.7 \pm 0.8$ & Melón de Olor & $\mathrm{S}$ & $3.8 \pm 0.4$ & $3.6 \pm 0.5$ & Verde G. & $\mathrm{S}$ & $4.0 \pm 0.0$ & $4.0 \pm 0.0$ \\
\hline Encin 4078 & $\mathrm{~S}$ & $2.9 \pm 0.7$ & $2.2 \pm 0.6$ & Cantaloup Haogen & Is & $3.8 \pm 0.4$ & $3.6 \pm 0.7$ & Tendral & $\mathrm{S}$ & $4.0 \pm 0.0$ & $4.0 \pm 0.0$ \\
\hline Piñonet & $\mathrm{S}$ & $2.9 \pm 0.8$ & $2.4 \pm 0.4$ & ANC-13 & $\mathrm{S}$ & $3.8 \pm 0.4$ & $3.8 \pm 0.4$ & Tempranillo & $\mathrm{S}$ & $4.0 \pm 0.0$ & $4.0 \pm 0.0$ \\
\hline Amarillo O. Tardío & $\mathrm{S}$ & $2.9 \pm 0.8$ & $2.5 \pm 0.8$ & Comun & $\mathrm{S}$ & $3.9 \pm 0.4$ & $3.4 \pm 0.7$ & PMR-45 & $\mathrm{U}$ & $4.0 \pm 0.0$ & $4.0 \pm 0.0$ \\
\hline Mollerusa7 & $\mathrm{S}$ & $3.0 \pm 0.9$ & $1.5 \pm 0.4$ & BG-6010 & Z & $3.9 \pm 0.3$ & $3.7 \pm 0.4$ & Pipa Blanca & $\mathrm{S}$ & $4.0 \pm 0.0$ & $4.0 \pm 0.0$ \\
\hline Amarillo Alargado & $\mathrm{S}$ & $3.0 \pm 1.0$ & $2.1 \pm 0.6$ & Banda de Godoy & $\mathrm{S}$ & $3.9 \pm 0.6$ & $3.8 \pm 0.6$ & Moscatel Grande & S & $4.0 \pm 0.0$ & $4.0 \pm 0.0$ \\
\hline NC-44082 & $\mathrm{S}$ & $3.0 \pm 0.0$ & $2.5 \pm 0.7$ & BG-4078 & $\mathrm{S}$ & $3.9 \pm 0.6$ & $3.9 \pm 0.3$ & Moscatel & $\mathrm{S}$ & $4.0 \pm 0.0$ & $4.0 \pm 0.0$ \\
\hline Loperano & $\mathrm{S}$ & $3.0 \pm 0.9$ & $3.0 \pm 0.8$ & C-247 & $\mathrm{L}$ & $3.9 \pm 0.3$ & $4.0 \pm 0.0$ & EC-1 & $\mathrm{S}$ & $4.0 \pm 0.0$ & $4.0 \pm 0.0$ \\
\hline Invernizo & $\mathrm{S}$ & $3.0 \pm 1.2$ & $3.0 \pm 0.9$ & ANC-46 & $\mathrm{S}$ & $4.0 \pm 0.0$ & $3.0 \pm 0.7$ & De Buena Clase & $\mathrm{S}$ & $4.0 \pm 0.0$ & $4.0 \pm 0.0$ \\
\hline Encin 064 & $\mathrm{~S}$ & $3.0 \pm 1.0$ & $3.0 \pm 1.2$ & Hidalgo & $\mathrm{S}$ & $4.0 \pm 0.0$ & $3.1 \pm 0.7$ & Cum-372 & I & $4.0 \pm 0.0$ & $4.0 \pm 0.0$ \\
\hline Del País & $\mathrm{S}$ & $3.0 \pm 0.8$ & $3.0 \pm 0.8$ & Cum-355 & I & $4.0 \pm 0.0$ & $3.1 \pm 0.7$ & Cum-334 & Tad & $4.0 \pm 0.0$ & $4.0 \pm 0.0$ \\
\hline Esento & $\mathrm{S}$ & $3.2 \pm 1.2$ & $3.0 \pm 1.0$ & ANC-48 & $\mathrm{S}$ & $4.0 \pm 0.0$ & $3.3 \pm 0.5$ & Cum-333 & Tad & $4.0 \pm 0.0$ & $4.0 \pm 0.0$ \\
\hline Amarilo Export. & $\mathrm{S}$ & $3.3 \pm 0.5$ & $3.0 \pm 0.5$ & WMR-29 & $\mathrm{U}$ & $4.0 \pm 0.0$ & $3.5 \pm 0.4$ & Caña Dulce & $\mathrm{S}$ & $4.0 \pm 0.0$ & $4.0 \pm 0.0$ \\
\hline Franceset & $\mathrm{S}$ & $3.4 \pm 0.8$ & $3.0 \pm 0.9$ & Tendral V. & $\mathrm{S}$ & $4.0 \pm 0.0$ & $3.5 \pm 0.6$ & CA-101084-C & $\mathrm{S}$ & $4.0 \pm 0.0$ & $4.0 \pm 0.0$ \\
\hline Rochet & $\mathrm{S}$ & $3.4 \pm 1.2$ & $3.4 \pm 0.5$ & Mollerusal & $\mathrm{S}$ & $4.0 \pm 0.0$ & $3.5 \pm 0.5$ & C-300 & $\mathrm{S}$ & $4.0 \pm 0.0$ & $4.0 \pm 0.0$ \\
\hline ANC-57 & $\mathrm{S}$ & $3.5 \pm 0.8$ & $2.8 \pm 0.7$ & Maduro N. & $\mathrm{S}$ & $4.0 \pm 0.0$ & $3.5 \pm 0.5$ & C-189 & $\mathrm{J}$ & $4.0 \pm 0.0$ & $4.0 \pm 0.0$ \\
\hline Escrito & $\mathrm{S}$ & $3.5 \pm 0.8$ & $3.0 \pm 1.0$ & MA 09-1084-1C & $\mathrm{S}$ & $4.0 \pm 0.0$ & $3.5 \pm 0.9$ & C-178 & - & $4.0 \pm 0.0$ & $4.0 \pm 0.0$ \\
\hline Encin 4069 & $\mathrm{~S}$ & $3.5 \pm 0.5$ & $3.2 \pm 1.2$ & Cum-129 & $\mathrm{Tu}$ & $4.0 \pm 0.0$ & $3.5 \pm 0.5$ & C-167 & Ser & $4.0 \pm 0.0$ & $4.0 \pm 0.0$ \\
\hline De la Marina & $\mathrm{S}$ & $3.5 \pm 1.0$ & $3.2 \pm 1.0$ & C-87 & - & $4.0 \pm 0.0$ & $3.7 \pm 0.4$ & C-41 & $\mathrm{J}$ & $4.0 \pm 0.0$ & $4.0 \pm 0.0$ \\
\hline Rayado & $\mathrm{S}$ & $3.6 \pm 0.8$ & $2.0 \pm 0.0$ & BG-6017 & $\mathrm{Z}$ & $4.0 \pm 0.0$ & $3.5 \pm 0.7$ & Bolas & $\mathrm{S}$ & $4.0 \pm 0.0$ & $4.0 \pm 0.0$ \\
\hline Mochuelo & $\mathrm{S}$ & $3.6 \pm 0.5$ & $2.6 \pm 0.8$ & Tendral T & $\mathrm{S}$ & $4.0 \pm 0.0$ & $3.6 \pm 0.5$ & BG-069 & $\mathrm{S}$ & $4.0 \pm 0.0$ & $4.0 \pm 0.0$ \\
\hline CA $13-11-1 C$ & $\mathrm{~S}$ & $3.6 \pm 0.7$ & $2.6 \pm 1.0$ & Simama & $\mathrm{T}$ & $4.0 \pm 0.0$ & $3.6 \pm 0.7$ & ANC-68 & $\mathrm{S}$ & $4.0 \pm 0.0$ & $4.0 \pm 0.0$ \\
\hline BG-6006 & Z & $3.6 \pm 0.6$ & $3.2 \pm 0.9$ & Rochel & $\mathrm{S}$ & $4.0 \pm 0.0$ & $3.6 \pm 0.7$ & $\begin{array}{l}\text { Amarillo } \\
\text { Manchado }\end{array}$ & $\mathrm{S}$ & $4.0 \pm 0.0$ & $4.0 \pm 0.0$ \\
\hline P.S.M. & $\mathrm{S}$ & $3.6 \pm 0.8$ & $3.3 \pm 0.5$ & CM 17187 & In & $4.0 \pm 0.0$ & $3.6 \pm 0.5$ & Adzur & - & $4.0 \pm 0.0$ & $4.0 \pm 0.0$ \\
\hline Mochuelos & $\mathrm{S}$ & $3.6 \pm 0.7$ & $3.5 \pm 1.0$ & Mollerusa2 & $\mathrm{S}$ & $4.0 \pm 0.0$ & $3.6 \pm 0.7$ & Controls & & & \\
\hline CMC-7 & $\mathrm{S}$ & $3.6 \pm 0.4$ & $3.5 \pm 1.2$ & Melao & $\mathrm{P}$ & $4.0 \pm 0.0$ & $3.6 \pm 0.5$ & & & & \\
\hline Agostizo & $\mathrm{S}$ & $3.6 \pm 0.4$ & $3.5 \pm 0.8$ & BG-078 & $\mathrm{S}$ & $4.0 \pm 0.0$ & $3.6 \pm 1.0$ & Charentais $\mathrm{T}$ & $\mathrm{F}$ & $4.0 \pm 0.0$ & $4.0 \pm 0.0$ \\
\hline Negros & $\mathrm{S}$ & $3.6 \pm 0.3$ & $3.6 \pm 1.2$ & Pedroso & $\mathrm{S}$ & $4.0 \pm 0.0$ & $3.7 \pm 0.7$ & Charentais Fom 1 & $\mathrm{~F}$ & $4.0 \pm 0.0$ & $4.0 \pm 0.0$ \\
\hline C- 173 & $\mathrm{~T}$ & $3.7 \pm 0.9$ & $3.1 \pm 0.7$ & Negro & $\mathrm{S}$ & $4.0 \pm 0.0$ & $3.7 \pm 0.7$ & Charentais Fom 2 & $\mathrm{~F}$ & $4.0 \pm 0.0$ & $4.0 \pm 0.0$ \\
\hline Cum-241 & $\mathrm{R}$ & $3.7 \pm 0.5$ & $3.5 \pm 0.7$ & CMC-23 & $\mathrm{S}$ & $4.0 \pm 0.0$ & $3.7 \pm 0.4$ & Cum-334 & $\mathrm{T}$ & $4.0 \pm 0.0$ & $4.0 \pm 0.0$ \\
\hline ANC-36 & $\mathrm{S}$ & $3.7 \pm 0.8$ & $3.2 \pm 0.9$ & Amarillo B. Pĩnón & $\mathrm{S}$ & $4.0 \pm 0.0$ & $3.7 \pm 0.6$ & Dinero & It & $1.2 \pm 0.7$ & $0.8 \pm 0.6$ \\
\hline Maduro A. & $\mathrm{S}$ & $3.7 \pm 0.8$ & $3.3 \pm 1.0$ & PI 161375 & $\mathrm{~K}$ & $4.0 \pm 0.0$ & $3.8 \pm 0.4$ & & & & \\
\hline
\end{tabular}

${ }^{\mathrm{z}}$ The inoculation was done following Oumouloud et al. (2009). Accessions are arranged in order of decreasing resistance based on disease ratings for pathotype $1.2 \mathrm{Y}$.

${ }^{\mathrm{y}} \mathrm{F}=$ France $; \mathrm{G}=$ Greece; $\mathrm{I}=$ Irak; In = India; Is = Israel; It = Italy; J = Japan; K = Korea; L = Lybia; P = Portugal; R= Russia; $\mathrm{S}=$ Spain; Ser = Serbia; T = Turkey; $\mathrm{U}=\mathrm{USA}$; Tad = Tadjikistan; Tu = Turkestan; $\mathrm{Z}=$ Zimbabwe; $-=$ unknown.

${ }^{x}$ The reaction severity was determined according with the scale: $0=$ no apparent symptoms; $1=$ beginning of wilting or yellowing on leaves; $2=$ leaves heavily affected; 3 = all leaves completely wilted, stem standing; and $4=$ dead plant.

${ }^{w}$ Each value represents the mean value of the reaction severity for 12 plants. The reaction severity was determined according to the scale: $0=$ no apparent symptoms; 1 = beginning of wilting or yellowing on leaves; $2=$ leaves heavily affected; $3=$ all leaves completely wilted, stem standing; and $4=$ dead plant.

inoculation according to the scale described subsequently.

Disease severity was assessed using the following scale: $0=$ no symptoms; $1=$ beginning of wilting or yellowing on leaves; 2 = leaves heavily affected by wilting or yellowing; 3 = all leaves completely wilted, stem standing; and $4=$ dead plant.

Tray method inoculation. This method proved to be very aggressive because resistant accessions or lines like Kogane Nashi Makuwa or Dinero showed some disease symptoms such as yellowing or wilting of leaves. Therefore, to identify sources of partial resistance, a less aggressive inoculation method was used for those accessions that showed a mean symptom score lower than 3 when inoculated with at least one pathotype using the above method. This method was previously described by Perchepied and Pitrat (2004). Seedlings were grown in trays containing sterilized sand under the same conditions as described previously. However, in this experiment, when the first true leaf began to appear, the trays were dipped in a conidial suspension $\left(3 \times 10^{6}\right.$ spores $\left./ \mathrm{mL}\right)$ and remained in this suspension in a growth chamber $\left(28^{\circ} \mathrm{C}\right.$ : 16 -h day, $20^{\circ} \mathrm{C}: 8$-h night). At least 12 seedlings for each pathotype and accession were inoculated. Plants were rated for symptoms $28 \mathrm{~d}$ after inoculation using the 0 to 4 scale described previously.

With these data, an analysis of variance was performed for each pathotype to evaluate the significance of the differences in the level of resistance among the accessions. Means were separated using the Tukey's b test ( $\alpha \leq$ 0.05 ). Data analysis was performed with the Statistical Analysis System (SAS Institute, Cary, NC).

\section{Morphological evaluation of the resistant accessions}

The 12 accessions that showed score values lower than 3 when inoculated with at least one pathotype using the less aggressive method were morphologically characterized to assess their suitability as F.o.m. race 1.2 resistance sources.

Melon plants in the two-leaf stage were transplanted to the field at Zaragoza (Spain) according to a completely randomized design using five plants per plot and five plots per accession. Morphological characterization was performed on the first fruit from each plant that was collected at maturity, which was visually indicated by the leaf next to the pedicel starting to dry. Cultivars Piel de Sapo, Amarillo Oro, and Doublon were used as reference genotypes, because they represented the commercial types usually grown in Spain. Five qualitative traits were visually determined (sex expression, fruit and flesh color, and the presence or absence of fruit netting and ribs); and three quantitative traits (fruit weight, total soluble solid content, and fruit shape) were also measured. Total soluble solid content was estimated using the refractive index ( ${ }^{\circ}$ Brix), which was measured with 
a manual refractometer. The fruit shape index was determined as the ratio of fruit length to fruit diameter. When this ratio nears 1 , the fruit shape is round; if it is greater than 1 and less than 1.3, the shape is oval or elongated if it is greater than 1.3; and if it is less than 1, the fruit shape would be flat.

\section{Results and Discussion}

Results of the resistance screen using the most aggressive inoculation procedure are shown in Table 1. Typical symptoms of fusarium wilt were observed in all the inoculated seedlings of the susceptible lines Charentais T, Charentais-Fom1, CharentaisFom2, and Cum-334, whereas all of the inoculated seedlings of the resistant control 'Dinero' showed only mild symptoms. This reaction indicates that the two F.o.m. isolates used in this experiment belong to race 1.2. Moreover, isolate Fom 0125 induced leaf yellowing before plant death, whereas seedlings inoculated with isolate Fom $37 \mathrm{mls}$ wilted and died without yellowing symptoms, which confirms that those isolates belong to pathotypes $1.2 \mathrm{Y}$ and $1.2 \mathrm{~W}$, respectively. The first symptoms of fusarium wilt were observed in the susceptible seedlings as early as $5 \mathrm{~d}$ after inoculation, and plants died within $15 \mathrm{~d}$. It is possible that we observed rapid wilting in our experiments because we used higher spore concentrations $\left(3 \times 10^{6}\right.$ spores $\left./ \mathrm{mL}\right)$ compared with those used by previous studies $\left(1 \times 10^{6}\right.$ spores $\left./ \mathrm{mL}\right)$ (Alvarez et al., 2005; Zink and Thomas, 1990). A correlation between wilt severity and inoculum concentration has been reported (Douglas, 1970), which could further explain the rapid wilting observed in our experiment.

All of the accessions tested in this experiment appeared to have a high degree of susceptibility to both pathotypes of F.o.m. race 1.2, except Baza, BG-5384, Kogane Nashi Makuwa, C-211, Korça, and Shiro Uri Okayama, which only showed some mild fusarium symptoms $15 \mathrm{~d}$ after inoculation. Other accessions appeared partially resistant to pathotype $\mathrm{W}$ but were highly susceptible to pathotype Y (Table 1). Pathotype Y seems to be more aggressive than pathotype $\mathrm{W}$ because it generally induces more severe symptoms. These results agree with those of Gomez Vazquez and Tello (2000) who analyzed 14 isolates of F.o.m. race 1.2 and found that those belonging to pathotype $1.2 \mathrm{Y}$ were more aggressive than those belonging to pathotype $1.2 \mathrm{~W}$.

The previously described resistances in melon to race 1.2 of F.o.m. appeared to be partial and polygenically inherited (Perchepied et al., 2005; Perchepied and Pitrat, 2004), except for the complete resistance described on line BIZ by Herman and Perl Treves (2007).

The appearance of fusarium wilt symptoms after artificial inoculation may be influenced by the genetic background of the plant (Mas et al., 1981) and by environmental factors (Cohen et al., 1996). The method of inoculation used here was used by our team in previous studies (Oumouloud et al., 2009) and had produced reliable results within a few days. However, this method resulted in high disease levels, probably as a result of increased wounding of the seedling roots when removing them from the sand and the continuous exposure of the entire root system to a high concentration of the inoculum. This method may be considered too aggressive because such a high concentration of inoculum makes it difficult to detect partial resistance. However, Baza showed a higher level of resistance when using this aggressive method. Because all Baza plants showed fusarium wilt symptoms, this result could not be attributable to inoculation escapes. Instead we believe that the higher level of resistance can be attributed to some interaction of this accession with the inoculation method. Further studies of the different interactions are needed to elucidate the differences in resistance to F.o.m. race 1.2 in melon.

For detecting low levels of resistance, which could not be observed using this aggressive inoculation method, the accessions that showed mean score values lower than 3 when inoculated with at least one of the pathotypes were tested again using the less aggressive inoculation method described before. Table 2 shows the results obtained after this inoculation. Accessions Kogane Nashi Makuwa, C-211, and Shiro Uri Okayama showed very high levels of resistance to both pathotypes. Also, BG-5384 and $\mathrm{C}-181$ appeared to be highly resistant despite displaying slightly lower resistance levels. The accessions ANC-57, Baza, Encin 4078, Korça, Mollerusa-7, Piñonet, and Rayado proved to have some resistance to pathotype $1.2 \mathrm{~W}$ and are susceptible to pathotype $1.2 \mathrm{Y}$. The remaining accessions were susceptible to both pathotypes; however, as can be observed in Table 2, there are important differences in resistance levels. These data may suggest that the resistance to these two pathotypes is controlled by different genes, so the isolates we are using could be different races rather than different pathotypes from the same race. However, the difference in resistance could be also explained by differences in aggressivity between the two pathotypes. A third explanation for our results is that the resistances seen were polygenically inherited, which agrees with the observation by Perchepied and Pitrat (2004) that quantitative, polygenic, race non-specific resistance often shows small race-specific effects.

Kogane Nashi Makuwa and C-211 have already been described as resistant to F.o.m. race 1.2 by Oumouloud et al. (2009). C-211 is an andromonoecious accession provided by the E.E. "La Mayora" (Málaga, Spain) that shows similar morphological characteristics to Kogane Nashi Makuwa, which has a monoecious sex expression.

Accessions Kogane Nashi Makuwa, C-211, and Shiro Uri Okayama, all of which show almost complete resistance, as well as C-181, which shows a lower level of resistance to both pathotypes, have a Far Eastern origin, confirming that the Far East is a rich area for resistance sources to this race of F.o.m. Another accession, BG-5384, which is highly
Table 2. Reaction of 18 melon accessions to inoculation with pathotypes $\mathrm{Y}$ and $\mathrm{W}$ of F.o.m., using a less aggressive method. ${ }^{\mathrm{z}}$

\begin{tabular}{|c|c|c|}
\hline \multirow[b]{2}{*}{ Accession } & \multicolumn{2}{|c|}{ Pathotype } \\
\hline & $1.2 \mathrm{Y}$ & $1.2 \mathrm{~W}$ \\
\hline $\begin{array}{l}\text { Shiro Uri } \\
\text { Okayama }\end{array}$ & $0.4^{\mathrm{y}} \pm 0.6 \mathrm{a}$ & $0.2 \pm 0.4 \mathrm{a}$ \\
\hline $\begin{array}{l}\text { Kogane Nashi } \\
\text { Makuwa }\end{array}$ & $0.6 \pm 0.6 \mathrm{ab}$ & $0.1 \pm 0.2 \mathrm{a}$ \\
\hline C-211 & $0.8 \pm 0.74 \mathrm{ab}$ & $0.5 \pm 0.64 \mathrm{ab}$ \\
\hline BG-5384 & $1.7 \pm 0.74 b$ & $1.3 \pm 0.51 \mathrm{~b}$ \\
\hline C-181 & $2.2 \pm 0.71 \mathrm{bc}$ & $1.9 \pm 0.3 \mathrm{bc}$ \\
\hline Piñonet & $3.0 \pm 0.6 \mathrm{~cd}$ & $2.0 \pm 0.1 \mathrm{bc}$ \\
\hline Baza & $3.0 \pm 0.77 \mathrm{~cd}$ & $2.1 \pm 0.57 \mathrm{c}$ \\
\hline Encin 4108 & $3.1 \pm 0.7 \mathrm{~cd}$ & $2.9 \pm 0.8 \mathrm{~d}$ \\
\hline CA-13-11-1C & $3.3 \pm 0.64 \mathrm{~d}$ & $3.0 \pm 0.77 \mathrm{~d}$ \\
\hline $\begin{array}{l}\text { Amarillo } \\
\text { Alargado }\end{array}$ & $3.4 \pm 0.45 \mathrm{~d}$ & $3.2 \pm 0.64 \mathrm{~d}$ \\
\hline ANC-57 & $3.4 \pm 0.62 \mathrm{~d}$ & $2.1 \pm 0.7 \mathrm{c}$ \\
\hline Encin 4078 & $3.4 \pm 0.8 \mathrm{~d}$ & $1.8 \pm 0.74 \mathrm{bc}$ \\
\hline NC-44082 & $3.4 \pm 0.6 \mathrm{~d}$ & $3.4 \pm 0.5 \mathrm{~d}$ \\
\hline Rayado & $3.4 \pm 0.4 \mathrm{~d}$ & $2.1 \pm 0.7 \mathrm{c}$ \\
\hline Mochuelo & $3.5 \pm 0.66 \mathrm{~d}$ & $3.6 \pm 0.6 \mathrm{~d}$ \\
\hline Mollerusa 7 & $3.7 \pm 0.64 \mathrm{~d}$ & $2.1 \pm 0.7 \mathrm{c}$ \\
\hline $\begin{array}{l}\text { Amarillo Oval } \\
\text { Tardío }\end{array}$ & $4.0 \pm 0.0 \mathrm{~d}$ & $4.0 \pm 0.0 \mathrm{e}$ \\
\hline Korça & $4.0 \pm 0.0 \mathrm{~d}$ & $2.0 \pm 0.63 \mathrm{bc}$ \\
\hline & Controls & \\
\hline Dinero & $0.2 \pm 0.4$ & $0.0 \pm 0.0 \mathrm{a}$ \\
\hline Cum 334 & $3.8 \pm 0.4 \mathrm{~d}$ & $4.0 \pm 0.0 \mathrm{e}$ \\
\hline Charentais-Fom 2 & $3.8 \pm 0.4 \mathrm{~d}$ & $3.8 \pm 0.4 \mathrm{de}$ \\
\hline Charentais-Fom 1 & $3.9 \pm 0.3 \mathrm{~d}$ & $3.6 \pm 0.6 \mathrm{de}$ \\
\hline Charentais $\mathrm{T}$ & $4.0 \pm 0.0 \mathrm{~d}$ & $3.8 \pm 0.4 \mathrm{de}$ \\
\hline
\end{tabular}

${ }^{2}$ The inoculation was done as described by Perchepied and Pitrat (2004). Accessions are shown in order of decreasing resistance.

${ }^{\mathrm{y}}$ Each value represents the mean value of the reaction severity for 12 plants. The reaction severity was determined according to the scale: $0=$ no apparent symptoms; 1 = beginning of wilting or yellowing on leaves; $2=$ leaves heavily affected; $3=$ all leaves completely wilted, stem standing; and $4=$ dead plant. Values followed by different letters are significantly different according to the Tukey's b test.

resistant to both pathotypes, and ANC-57, Baza, Encin 4078, Mollerusa 7, Piñonet, and Rayado, which are all highly resistant to pathotype W, come from the Iberian Peninsula. Korça, also highly resistant to pathotype $\mathrm{W}$, comes from Russia.

When introducing disease resistance into commercial cultivars, it is important that the resistance source is morphologically similar to the commercial parents to avoid backcrossing for many generations. For this reason, we performed a morphological characterization of the 12 melon accessions that showed a modicum of resistance. The morphologically typified accessions, together with the results of this characterization, are shown in Table 3.

The resistance sources to F.o.m. race 1.2 previously identified belong to the botanical varieties conomon or makuwa, which are morphologically divergent from the cultivated melons in the Western countries that belong to the inodorus, cantalupensis, or reticulatus varieties. The results obtained in this study show for the first time that a relatively high level of resistance is detected in a cantalupensis accession, BG-5384. Some resistance to less aggressive isolates of this 
Table 3. Botanical variety, origin, sex expression, and fruit characteristics of melon accessions that have shown some level of resistance to at least one pathotype of Fusarium oxysporum f.sp. melonis race 1.2.

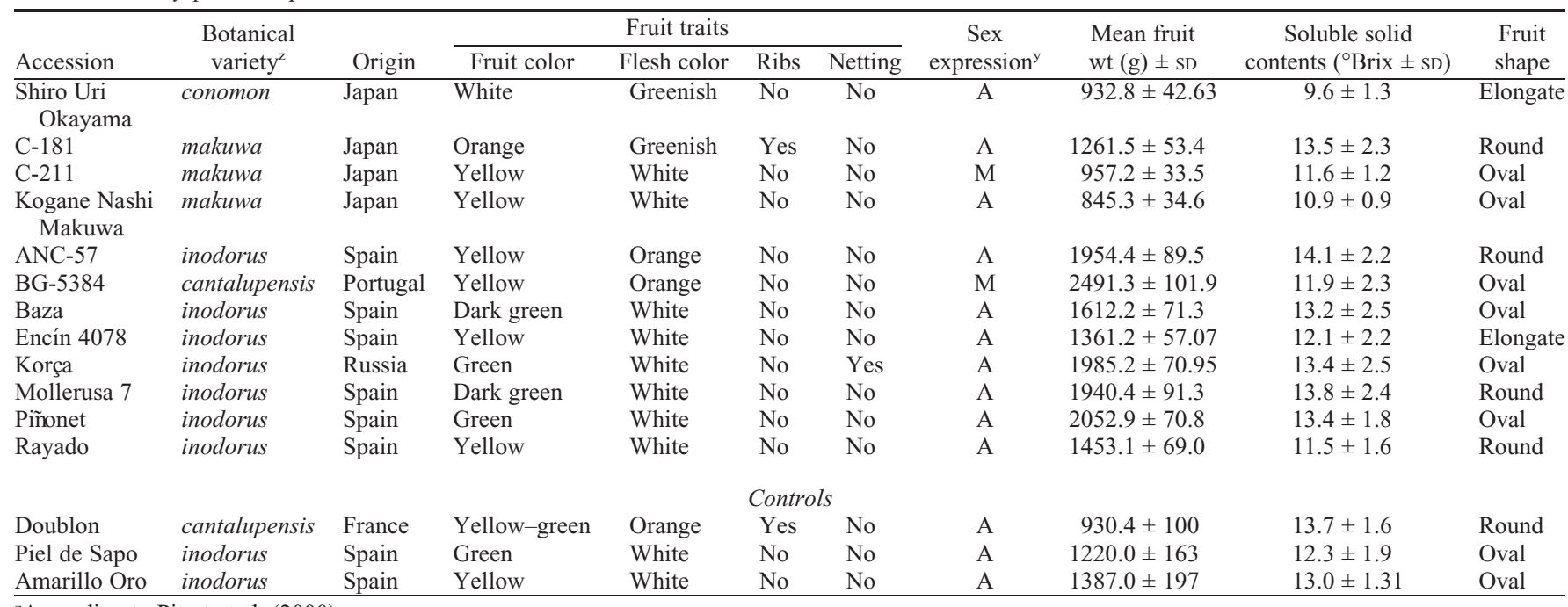

${ }^{\mathrm{z}}$ According to Pitrat et al. (2000).

${ }^{\mathrm{y}} \mathrm{A}=$ andromonoecious; $\mathrm{M}=$ monoecious.

fungus has also been found within some inodorus accessions (Table 2).

Most of the resistant accessions are andromonoecious; only Kogane Nashi Makuwa and BG-5384, which both show high levels of resistance, appear to be monoecious. Monoecious genotypes may be easily used in hybrid seed production as female parents because pistillate flowers do not need to be emasculated. There is a linkage between monoecious sex expression and oval and elongated fruit shape that should be broken to develop round-fruit types (Risser, 1984); however, this linkage is not very tight because some cultivars and exotic materials show a monoecious sex expression and round fruits (Monforte et al., 2005).

Fruit and flesh color, fruit shape and weight, and soluble solid contents are important melon fruit characteristics from a commercial point of view (Eduardo et al., 2007; Singh et al., 1976). Variations were recorded for skin and flesh color, presence or absence of ribs, and netting among the characterized accessions. Commercial fruit shapes range from round to oval; generally elongated fruits are less favored by the markets. Many of the resistant accessions, particularly the highly resistant C-211, Kogane Nashi Makuwa, and BG-5384, are oval-shaped, which is suitable when used as parentals for developing resistant commercial cultivars.

Melon breeders consider fruit weight one of the most important commercial characteristics (Chonkar et al., 1979; Monforte et al., 2005). However, within the commercial types, desirable fruit weight ranged, according to the botanical variety, between 700 and $1300 \mathrm{~g}$ for cantalupensis and reticulatus cultivars and from 1500 to more than $3000 \mathrm{~g}$ for the Spanish traditional inodorus type "Piel de Sapo" (Gomez-Guillamon et al., 1998). Thus, BG5384, which had the highest mean fruit weight, could also be a good candidate for introducing resistance into the "Piel de Sapo" types.

Finally, soluble solid content influences quality. In the Spanish market, melons below $12^{\circ}$ Brix are refused (Gomez-Guillamon et al., 1998). As expected, the accessions from the Iberian Peninsula showed soluble solid contents higher than those from the Far East and could be used as parentals for introducing resistance into Iberian commercial genotypes, particularly BG-5384, which showed significant levels of resistance. BG-5384 is morphologically very similar to the Spanish typical inodorus types (Piel de Sapo, Amarillo Oro); only its orange flesh color could be a problem when introducing resistance into these types. However, it is far more favorable to use BG5384 than to use the Far Eastern makuwa and conomon accessions.

This is the first time that high resistance to the race 1.2 of F.o.m. has been reported in melon materials from the Iberian Peninsula, which are morphologically diverse from melons of Far Eastern origin. Specifically, BG-5384 shows a high level of resistance and may be exploited either as a resistant melon rootstock or as a source for resistance in commercial cantalupensis or inodorus lines. However, the resistance level of BG-5384 is significantly lower than the level of resistance in the makuwa and conomon accessions, so it will be useful to use both sources of resistance to reach the highest level of resistance. Our results (data not published) point to resistance in BG-5384 as quantitatively controlled being the additive effects always positive and significant, so it will be possible to increase the number of resistance alleles and subsequently, the level of resistance in this accession by selfing and selecting the plants with the highest level of resistance.

Further characterization of this resistance is needed before it can be incorporated into melon breeding programs.

\section{Literature Cited}

Alvarez, J.M., R. Gonzalez-Torres, C. Mallor, and M.L. Gomez-Guillamon. 2005. Potential sour- ces of resistance to fusarium wilt and powdery mildew in melons. HortScience 40:1657-1660.

Bates, D.M. and R.W. Robinson. 1995. Cucumber, melons and watermelons, Cucumis and Citrullus (Cucurbitaceae), p. 89-111. In: Smartt, J. and N.W. Simmonds (eds.). Evolution of crop plants. John Wiley \& Sons, New York, NY.

Chonkar, V.I., D.N. Singh, and R.I. Singh. 1979. Genetic variability and correlation studies in muskmelon. Indian J. Agr. Sci. 49:361-363.

Cohen, R., B. Blaier, A.A. Schaffer, and J. Katan. 1996. Effect of acetochlor treatment on fusarium wilt and sugar content in melon seedlings. Eur. J. Plant Pathol. 102:45-50.

Douglas, D.R. 1970. The effect of inoculum concentration on the apparent resistance of muskmelons to Fusarium oxysporum f.sp. melonis. Can. J. Bot. 48:687-693.

Eduardo, I., P. Arus, A.J. Monforte, J. Obando, J.P. Fernandez-Trujillo, J.A. Martinez, J.M. Alvarez, and E. van der Knaap. 2007. Estimating the genetic architecture of fruit quality traits in melon using a genomic library of near isogenic lines. J. Amer. Soc. Hort. Sci. 132:80-89.

Ficcadenti, N., S. Sestili, S. Annibali, G. Campanelli, A. Belisario, M. Maccaroni, and L. Corazza. 2002. Resistance to Fusarium oxysporum f.sp. melonis race 1,2 in muskmelon lines 'Nad-1' and 'Nad-2'. Plant Dis. 86:897-900.

Freeman, S. and R.J. Rodriguez. 1993. A rapid inoculation technique for assessing pathogenecity of Fusarium oxysporum f.sp. niveum and F.o. f.sp. melonis on cucurbits. Plant Dis. 77:1198-1201.

Gamborg, O.L. and L.R. Wetter. 1975. Plant tissue culture methods. National Research Council of Canada, Saskatoon, Saskatchewan, Canada.

Gomez-Guillamon, M.L., E. Moriones, M. LuisArteaga, J.M. Alvarez, J.A. Tores, A.I. LopezSese, I. Canovas, F. Sanchez, and R. Camero. 1998. Morphological and disease resistance evaluation in Cucumis melo and its wild relatives, p. 53-61. In: Cucurbitaceae 98. Proc. Cucurbiatceae Conference Pacific Grove, CA, 30 Nov. to 4 Dec. 1998.

Gomez Vazquez, J. and J.C. Tello. 2000. Las semillas de melón (Cucumis melo L.) portadoras de diversos patotipos de Fusarium oxysporum f.sp. melonis. Bol. Sanid. Veg., Plagas $26: 35-45$ 
Herman, R. and R. Perl-Treves. 2007. Characterization and inheritance of a new source of resistance to Fusarium oxysporum f.sp. melonis race 1.2 in Cucumis melo. Plant Dis. 91:1180-1186.

Jeffrey, C. 1980. A review of the Cucurbitaceae. Bot. J. Linn. Soc. 81:233-247.

Mallick, M.F.R. and M. Masui. 1986. Origin, distribution and taxonomy of melons. Sci. Hort. 28:251-261.

Martyn, R.D. and T.R. Gordon. 1996. Fusarium wilt of melon, p. 14-15. In: Zitter, T.A., D.A. Hopkins, and C.H. Thomas (eds.). Compendium of cucurbit diseases. American Phytopathological Society, St. Paul, MN.

Mas, P., P.M. Molot, and G. Risser. 1981. Fusarium wilt of muskmelon, p. 169-177. In: Nelson, P.E., T.A. Toessen, and R.J. Cook (eds.). Fusarium: Disease, biology and taxonomy. Pennsylvania State University Press, University Park, PA.

Monforte, A.J., I. Eduardo, S. Abad, and P. Arus. 2005. Inheritance mode of fruit traits in melon: Heterosis for fruit shape and its correlation with genetic distance. Euphytica 144:31-38.
Oumouloud, A., M.S. Arnedo-Andres, R. GonzalezTorres, and J.M. Alvarez. 2009. Morphological and molecular characterization of melon accessions resistant to fusarium wilts. Euphytica 169 69-79.

Perchepied, L. and M. Pitrat. 2004. Polygenic inheritance of partial resistance to Fusarium oxysporum f.sp. melonis race 1.2 in melon. Phytopathology 94:1331-1336.

Perchepied, L., C. Dogimont, and M. Pitrat. 2005. Strain-specific and recessive QTLs involved in the control of partial resistance to Fusarium oxysporum f.sp. melonis race 1.2 in a recombinant inbred line population of melon. Theor. Appl. Genet. 111:65-74.

Pitrat, M., P. Hanelt, and K. Hammer. 2000. Some comments on infraspecific classification of cultivars of melon. Acta Hort. 510:29-36.

Pitrat, M., G. Risser, F. Bertrand, D. Blancard, and H. Lecoq. 1996. Evaluation of a melon collection for disease resistances, p. 49-58. In: Cucurbits towards 2000. Proc. VII Eucarpia Meeting on Cucurbit Genetics and Breeding, Malaga, Spain.
Risser, G. 1984. Correlation between sex expression and fruit shape in muskmelon (Cucumis melo L.), p. 100-103. Cucumis and melons. Proc. III EUCARPIA Meeting, Plovdiv, Bulgaria.

Risser, G., Z. Banihashemi, and D.W. Davis. 1976. A proposed nomenclature of Fusarium oxysporum f.sp. melonis races and resistance genes in Cucumis melo. Phytopathology 66:11051106.

Risser, G. and J.C. Rode. 1973. Breeding for resistance to Fusarium oxysporum f.sp. melonis, p. 37-39. In: Risser, G. (ed.). Eucarpia: La Sélection du melon. INRA, MontfavetAvignon, France.

Singh, D.J., K.S. Nandpuri, and B.R. Sharma 1976. Inheritance of some economic quantitative characters in an intervarietal cross of muskmelon (Cucumis melo L.). J Res. 13: 172-176.

Zink, F.W. and C.E. Thomas. 1990. Genetics of resistance to Fusarium oxysporum f.sp. melonis races 0,1 , and 2 in muskmelon line MR-1. Phytopathology 80:1230-1232. 